\title{
HIV-related risk factors among male sex workers in different settings in Shenzhen, China
}

\author{
Jin Zhao ${ }^{1,2^{*}}$, Wen-De Cai ${ }^{2}$, Lin Chen ${ }^{2}$, Yong-Xia Gan², Yun-Yun Zi ${ }^{2}$, Jin-Quan Cheng ${ }^{2}$, Xiao-Rong Wang ${ }^{1}$, \\ Ming-Liang $\mathrm{He}^{1}$ \\ From $16^{\text {th }}$ International Symposium on HIV and Emerging Infectious Diseases \\ Marseille, France. 24-26 March 2010
}

\section{Background}

This study aims to investigate the prevalence of HIV infection and identify HIV-related risky behaviors of MSW in different settings in Shenzhen, China, in order to tailor the venue-based prevention interventions to this unique subgroup of men who have sex with men (MSM).

\section{Methods}

A total of 394 participants were randomly selected among MSW in Shenzhen, from April to July 2008, using time-location sampling. Each participant was asked to finish a guided self-adminstered questionaire, focusing on their behaviors and knowledge. Field observations were conducted at the same time. Their serological data were collected and tested for HIV, syphilis and HCV.

\section{Results}

Among 394 subjects, the prevalence of HIV infection was $5.1 \%$, with $6.9 \%$ among MSWs in parks (PMSW), $11.3 \%$ among MSWs in family clubs(FMSW, a kind of home-based brothels holding small group of MSWs <= 15 ) and $1.7 \%$ among MSWs in entertainment venues (EMSW, holding big group of MSWs $>15$ ). Syphilis prevalence was $14.2 \%$, with $25.0 \%$ in PMSWs, $17.6 \%$ in FMSW and $10.6 \%$ in EMSWs. Both HIV and syphilis prevalence were significantly different among different type of MSWs. Independent PMSWs and small grouping FMSWs had a higher proportion of self-identifying as homosexual/gay and fewer female sex partners, elder or higher polarization in age. In addition, a higher proportion of MSWs was found coming from provinces with higher HIV prevalence, and lower coverage by HIV-related education program and relevant services.

* Correspondence: szhaojin@gmail.com

${ }^{1}$ School of Public Health of Primary Care, The Chinese University of Hong Kong, Hong Kong, Hong Kong

\section{Discussion}

Different type of male sex work is associated with HIV infection. MSWs working in family clubs and parks are comparatively with higher risk of being infected, while MSWs working in big entertainment venues showed a lowest HIV prevalence within the past few years in Shenzhen. This situation indicated that current HIV prevention intervention strategy that focus on big venues is quiet effective and should be expanded to cover the MSM population frequenting small venues.

\section{Author details}

${ }^{1}$ School of Public Health of Primary Care, The Chinese University of Hong Kong, Hong Kong, Hong Kong. ${ }^{2}$ Shenzhen Center for Disease Control and Prevention, Shenzhen, PR China.

Published: 11 May 2010

\section{doi:10.1186/1742-4690-7-S1-P100}

Cite this article as: Zhao et al:: HIV-related risk factors among male sex workers in different settings in Shenzhen, China. Retrovirology 2010 7(Suppl 1):P100.
Submit your next manuscript to BioMed Central and take full advantage of:

- Convenient online submission

- Thorough peer review

- No space constraints or color figure charges

- Immediate publication on acceptance

- Inclusion in PubMed, CAS, Scopus and Google Scholar

- Research which is freely available for redistribution

Submit your manuscript at www.biomedcentral.com/submit
C Biomed Central 